\title{
Orden global, agricultura contractual y campesinado: el circuito tabacalero de la provincia de Misiones, Argentina (1990-2012) ${ }^{1}$
}

\author{
Sebastián Gómez Lende ${ }^{2}$
}

\begin{abstract}
RESUMEN
Orden global es sinónimo de desorden local. El propósito de este trabajo es estudiar la dialéctica entre orden global y lógicas locales en el circuito del tabaco Burley de la provincia de Misiones (Argentina) entre 1990 y 2012; partiendo de un pormenorizado análisis de la bibliografía especializada y la información suministrada por organismos públicos y privados, se abordará el nuevo modelo de organización socioterritorial local, basado en la cientifización del trabajo agropecuario, la subordinación del campesinado a la agroindustria transnacional -vía agricultura bajo contrato-, y políticas públicas funcionales a las grandes tabacaleras.
\end{abstract}

Palabras clave: Orden global y racionalidades locales; agricultura contractual y campesinado; circuito tabacalero.

\begin{abstract}
Global order is synonymous with local disorder. The purpose of this paper is to study the dialectic between global and local order in Burley's tobacco circuit in Misiones province (Argentina), between 1990 and 2012. This study is based on a detailed analysis of the literature and information provided by public and private agencies. The new local social and territorial organization patterns are described based on scientization of agricultural labor, the subordination of peasants -through contract farming-via transnational agribusiness, and public policies functional to big tobacco dealers.
\end{abstract}

Key words: Global order and local rationalities; contract farming and peasantry; circut of tobacco circuit.

1 Artículo recibido el 15 de junio de 2013, aceptado el 14 enero de 2014 y corregido el 17 de abril de 2014.
2 Centro de Investigaciones Geográficas-IGEHCSCONICET/ Universidad Nacional del Centro de la Provincia de Buenos Aires (Argentina).

E-mail: gomezlende@yahoo.com.ar 
Si el espacio geográfico es un conjunto indisoluble, solidario y contradictorio de objetos, acciones y normas, el territorio es, en sí mismo, el espacio explicado a partir de sus usos (Santos, 1996a; Santos \& Silveira, 2001). Sustentado en el auge del sistema de poder neoliberal, y conforme el papel cada vez más estratégico desempeñado por los satélites, las telecomunicaciones, la informática, la biotecnología, la genética, las finanzas y los servicios gana preponderancia, el período actual -el medio técnico-científico-informacionalafianza su presencia en el territorio gracias a la aceleración de las formas de circulación, la consolidación de la división socioespacial del trabajo -internacional y nacional-, la mayor especialización económica regional y la creciente tensión entre globalidad y localidad (Santos, 1996a, 1996b).

Omnipresente, la dialéctica que el capitalismo ha forjado entre el mercado y el Estado, lo nuevo y lo viejo, lo externo y lo interno (Santos, 1992), se expresa hoy día en el territorio como el contrapunto entre horizontalidades y verticalidades. Las verticalidades -emisarias y actos de imperio del orden global- son nexos organizacionales esto es, externos a los lugares- responsables por el funcionamiento general del territorio, y se articulan a una misma lógica económica -presidida por la internacionalización del capital, las actividades hegemónicas modernas y las regulaciones globales-; homogeneizando los aspectos técnicos y políticos de la producción, esas fuerzas instan a la obediencia de las reglas egoístas impuestas por los agentes dominantes -que operan exclusivamente al servicio del mercado-, desestructurando el medio en el cual operan -su impacto suele ser desintegrador, caótico, incoherente y anárquico para todos los demás actores (Santos, 2000)- y fomentando el uso del territorio como si de un mero recurso se tratara (Gottmann, 1975). Solidaridades orgánicas, de base local, revelan, en cambio, horizontalidades que forjan un tejido continuo y heterogéneo de modernidades/ obsolescencias de diferente edad y funcionalidad, cuyo objetivo esencial es asegurar la contigüidad espacial y la cohesión social local, contemplando al territorio no solo como recurso, sino también como abrigo: aquí surgen valoraciones no hegemónicas del trabajo colectivo (Silveira, 1999), como el apego al pasado y la tradición, a políticas públicas de intervención/redistribución, a prácticas/ técnicas pretéritas, y a producciones y/o formas de producción marginales.

Otra forma de entender ese contrapunto es analizando la coexistencia, en el territorio, de una métrica mercantil y una métrica burocrática (Guillaume, 1975): la primera siembra heterogeneidad y segmentación en el tejido social, la segunda procura reunir o compensar aquello que ha sido fragmentado por el mercado. Sin embargo, con el neoliberalismo el impacto de la métrica burocrática es limitado $y$, a menudo, a tal grado deformado, que termina coadyuvando a consumar los procesos que, en principio, pugnaba por revertir. En otras palabras, en vez de negar el orden global, las horizontalidades se reestructuran para afianzar su reproducción.

La ideología desempeña, ciertamente, un papel-clave en lo que atañe a la propagación de las verticalidades en los territorios nacionales y locales. Se difunde, en tal sentido, una narrativa sobre la modernización territorial que, asegurando un consenso social para esta, la impone, al nivel del imaginario colectivo, como proceso necesario e inevitable (Silveira, 1999). Surge entonces una fábula, una maquinación, una psicoesfera, un conjunto de ideas, creencias y pasiones que, estructuradas en un discurso relativamente coherente, proveen de reglas a la racionalidad (Santos, 1996a) y estimulan la adecuación comportamental a los valores sociales, técnicos y políticos de la modernidad. Su mensaje, persuasivo, manipulador, preñado de símbolos de progreso, creación de empleos y desarrollo regional y nacional (Silveira, 1999), arguye que la pobreza y la miseria solo pueden superarse generando condiciones propicias para los agentes hegemónicos; en verdad, la fábula no aspira a impulsar el largamente postergado 'desarrollo' de los lugares escogidos para la difusión, por parte del Estado y las empresas, del nuevo modelo, sino favorecer a ultranza los objetivos del capital, enmascarar su desidia y perversidad, y ocultar tanto el empeoramiento de las dificultades económicas, sociales y ambientales preexistentes, cuanto la generación de otras problemáticas, generalmente más graves que las anteriores. 
Sabido es que uno de los rasgos intrínsecos al período contemporáneo es el desplazamiento del eje de gravedad de la técnica, la ciencia y la información desde la ciudad a un campo penetrado por informaciones externas e intereses distantes -precios internacionales, innovaciones biotecnológicas, acumulación financiera, penetración del capital extranjero- que hacen tabla rasa de la historia pretérita y las herencias espaciales (Silveira, 1999). La contradictoria combinación de solidaridades organizacionales y orgánicas, cambio y permanencia, fuerzas verticales y horizontales, define cierta productividad espacial -la peculiar aptitud/posición de un país/lugar en la división del trabajo relativa a uno o más productos- (Santos 1996a), siempre matizada por la tensión entre una función que permanece -que brinda identidad a la región en virtud de la estabilidad de sus prácticas agrícolas (Roca, 1989)- y un cambio o transformación espacial (Silveira, 1999). Son estos los tiempos de la 'agricultura científica globalizada' (Santos, 2000), basada en una 'crono-expansión de la frontera agropecuaria' (Silveira, 1999) definida por la acumulación de técnicas e informaciones, la reestructuración de calendarios, la cientifización del trabajo agrícola y la aceptación de tiempos y exigencias externas que, implicando un aumento de la producción, imponen estricta obediencia a la lógica del capital globalizado, el cual se vale de 'paquetes tecnológicos' para someter a los productores al imperio de sus intereses y estrategias.

Lo que Hernández (2009) define como 'ruralidad globalizada' asume, en la Argentina, variadas formas; una de ellas se vincula a la globalización absoluta de cultivos y formas de producción, cuestión que, en nuestro país, se observa nítidamente en la acelerada y voraz expansión del binomio soja transgénica-siembra directa, variable-clave de la modernidad actual que, además de conquistar el área cerealera y oleaginosa tradicional (la pampa húmeda), se instaló en el norte del país para satisfacer la demanda internacional de granos, aceites, harinas y biocombustibles, acarreando graves problemáticas ambientales -deforestación, desertización, contaminación-: he aquí la forma pura de manifestación de la lógica dominante en los usos agrícolas del territorio.
Otro mecanismo de imposición de la racionalidad hegemónica -bastante más matizado que el anterior, pero igualmente perceptible en lo que concierne a las formas de organización técnica de la agricultura-, se manifiesta en algunos 'circuitos regionales de acumulación' o 'circuitos espaciales de la producción' (Moraes, 1988) de base agrícola -caña de azúcar, algodón, yerba mate, fruticultura, vitivinicultura, tabaco- propios de la llamada 'Argentina extrapampeana'; allí, a partir de la interconexión de actividades y eslabones vía nexos insumo-producto, surgen relaciones asimétricas (y conflictos) entre agentes dominantes y subordinados), los primeros apropiándose de parte de los excedentes generados por los segundos y de los recursos que el Estado inyecta al circuito para regularlo (Cariola \& Lacabana, 1986; Marqués, 1987). Es, precisamente, esa forma híbrida de globalización del medio rural la que se aborda en este trabajo.

Obstando especificidades puntuales, se trata, en todos los casos, de actividades marginales, en crisis que, incompletamente globalizadas -incapaces de subordinarse por completo a la racionalidad dominante (Santos, 1996a)-, comparten rasgos estructurales: a) son producciones periféricas a nivel nacional, pero emblemáticas y esenciales a escala regional; b) su primer eslabón (la producción agrícola) implica la coexistencia de agentes/ formas de producción capitalistas y precapitalistas; c) han sufrido repetidos y dramáticos episodios de reestructuración, especialmente durante la década de 1990 -concentración de tierras, paquetes tecnológicos, debilitamiento del campesinado y mayor integración vertical (aquí el sector agroindustrial/comercial asume control directo sobre parte de la producción primaria -autoabastecimiento de materia prima-, o impone la agricultura contractual). En este último caso, la agroindustria evita los riesgos de invertir en el eslabón primario, programando indirectamente el ciclo agrícola para asegurarse la provisión continua y estable de materia prima, y otorgándole al productor (en teoría) mayores certezas de venta del producto, precios y épocas de cobro, acceso al crédito y al cambio técnico, y continuidad de la actividad (Teubal \& Pastore, 1995). 
Vale la pena señalar, en tal sentido, que en casi todas las cadenas de acumulación regionales enumeradas, ambas modalidades de integración vertical coexisten y se complementan, aunque con marcada preponderancia de la integración por propiedad; la única excepción a dicha regla la constituye el tabaco misionero, donde la exclusividad de la agricultura contractual obedece a la casi absoluta primacía del campesinado como agente clave de la etapa primaria del circuito.

Existe consenso a nivel académico en cuanto a definir al 'campesinado' como productores minifundistas que, apegados a la tradición e incapaces de modernizarse técnicamente, diversifican cultivos/riesgos, utilizan fuerza de trabajo básicamente familiar y se insertan laboralmente en actividades extraprediales rurales/urbanas como asalariados temporales o semiproletarios para maximizar el ingreso familiar indivisible (Brignol \& Crispi, 1982). Sin embargo, y aunque la producción campesina sea eminentemente no capitalista, no resulta ajena a dicho sistema de acumulación, ni puede permanecer aislada de las lógicas que le son externamente impuestas; al contrario, sus estrategias de reproducción y supervivencia lo obligan a insertarse -regular o esporádicamente- en el mercado, y a asumir, en ese sentido, cierta 'funcionalidad' respecto del orden global: los campesinos proveen a la economía urbana de abundante fuerza de trabajo agrícola asalariada para las medianas y grandes empresas; configuran un creciente ejército de reserva que rebaja el nivel general de salarios de la sociedad; y la parte de su producción destinada al mercado obtiene precios muy bajos, en virtud de la autoexplotación de la fuerza de trabajo familiar y las lesivas condiciones impuestas por las agroindustrias (Barsky, 1990).

El campesino constituye, de hecho, la principal fuente de renta para el sector agroindustrial: la producción primaria queda completamente relegada a los agricultores familiares, cuya reproducción no capitalista permite al polo integrador ampliar sus beneficios $y$, al mismo tiempo, controlar la marcha del cultivo (Marsden et al., 1996). Obteniendo excedentes derivados de una relación salarial inexistente y la autoexplotación laboral, los agentes agroindustriales lucran con el crédito/adelanto de insumos, elevan arbitra- riamente sus exigencias y especulan con la imposibilidad del campesino de abandonar la actividad, aprovechándose de su dependencia técnico-financiera e imponiéndole condiciones de intercambio tan desfavorables que apenas le permiten alcanzar un umbral mínimo de subsistencia; esto supone, tarde o temprano, una ruptura en las solidaridades orgánicas que regulan el modo de vida del campesinado, ahora en parte suplantadas por pautas organizacionales o externas de comportamiento que lo obligan a resignar su autonomía de antaño y a ceder su poder de decisión. La agricultura contractual -expresión de una verticalidad- despoja al agricultor de autonomía, imponiendo pautas organizacionales -paquetes tecnológicos y contratos de compra-venta- que determinan los criterios esenciales de la actividad-cultivos, volumen, calidad, técnicas de producción, insumos a utilizar, plazos y condiciones de entrega, canales válidos de comercialización, etc-. En esa relación de subsunción formal del trabajo por el capital, la agricultura familiar resulta, para la agroindustria, más atractiva que una hipotética producción a gran escala, toda vez que le permite prescindir de trabajo asalariado e inversiones tecnológicas, y evitar conflictos sindicales (Slutzky, 2011).

\section{Origen y evolución histórica del cultivo de tabaco en la provincia de Misiones (1880- 1990)}

Originalmente, los primeros antecedentes de cultivo y consumo de tabaco se remontan al continente americano en su etapa precolombina, especialmente en la isla de San Salvador, Las Antillas, gran parte de México y el sur estadounidense; posteriormente, las expediciones de Rodrigo de Jerez, las iniciativas de Ramón Pane, las gestiones de Jean Nicot y los viajes de numerosos marineros españoles y portugueses alentarían y afianzarían, pese a las resistencias iniciales, su difusión en todo el planeta, especialmente en el Viejo Mundo. La conquista española del actual territorio argentino fomentó el cultivo de tabaco en el noroeste, especialmente en Salta y Jujuy, provincias a las que permaneció relegado hasta finales del siglo XIX. El Estado nacional alentó, en pleno modelo agroexportador 
(1880-1930), un vigoroso proceso de colonización del nordeste argentino, cuyo epicentro fue la provincia de Misiones, situada en la Ilamada 'triple frontera', y limitando al oeste con Paraguay, al este, norte y sur con Brasil, y al sudoeste con la provincia de Corrientes (Figura $\mathrm{N}^{0}$ 1). Su condición de territorio marginal y fronterizo, hasta entonces solo poblado por aborígenes y misiones jesuitas y las posibilidades económicas que representaba la riqueza de sus bosques y de sus yerbales vírgenes -aunadas a la necesidad de preservar la integridad territorial del país ante el entonces vigente litigio fronterizo con Brasil-, determinaron que, entre 1877 y 1930, fueran fundadas 25 colonias en la provincia de Misiones.

Inmigrantes suizos, alemanes y brasileños -oriundos, estos últimos, de regiones cariocas sometidas a procesos de minifundización, como Río Grande do Sul, y con experiencia en el desarrollo de cultivos subtropicales en la llamada 'escuela de la selva'-, fueron atraídos por las ventajas ofrecidas para acceder a la tierra, razón por la cual se instalaron en las colonias oficiales establecidas en el sur y centro provincial, surgidas a partir de la cesión de parcelas de tierras fiscales a condición de plantar yerba-mate y tabaco en cierto porcentaje de la superficie asignada; posteriormente, también adquirieron u ocuparon tierras fiscales, fundando, a su vez, colonias privadas en el Alto Paraná, todo lo cual fomentó la creación de un mercado de compra-venta de 'mejoras' - parcelas desmontadas con cierta infraestructura consolidada- (Girbal-Blacha, 2007; Gallero, 2009; García, 2011). El tabaco desempeñó un rol fundamental en el proceso colonizador, especialmente desde finales del siglo XIX hasta mediados del siglo XX: desde un comienzo, se configuró en una fuente básica de ingresos monetarios para la familia que recién se instalaba en su parcela; y, de hecho, podría

Figura $\mathrm{N}^{\circ} 1$

Argentina, según división político-territorial (provincias)

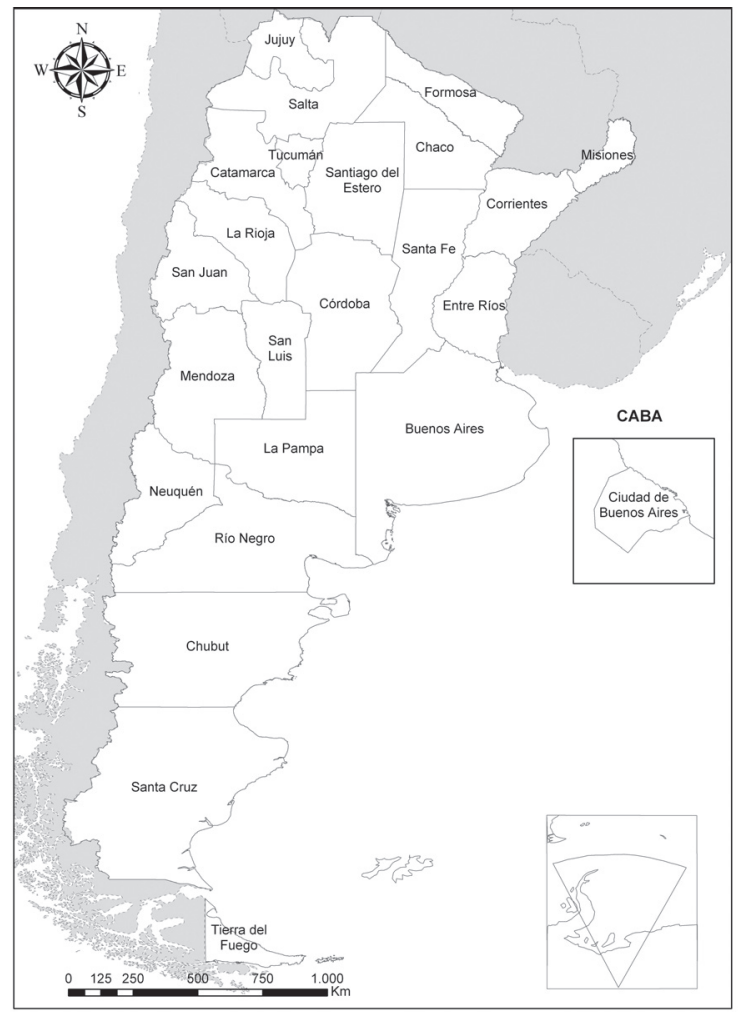

Fuente: Elaboración propia. 
aseverarse que la fuerza colonizadora a su vez impulsó al tabaco, y viceversa (Gallero, 2011), afianzando un esquema de poblamiento territorial basado en la roza y quema, en virtud de la excepcional fertilidad de la tierra luego del primer desmonte.

Operando vía una estructuración del territorio librada a la dinámica de sus propios actores sociales (Baranger, 2007), ese fenómeno obedeció tanto a la migración y la promoción colonizadora como a la integración de mercados y la relación legal con la tierra (García, 2011). Surgió así una economía familiar de subsistencia basada en la horticultura, la ganadería, la avicultura, y el cultivo de maíz, caña de azúcar, mandioca, forrajes, yerba y tabaco; puesto que, al ser un cultivo anual, permitía al colono obtener un rápido ingreso monetario, el tabaco fue durante largo tiempo el principal producto, gracias al capital adelantado por los acopiadores, su aptitud agroecológica respecto de los suelos recién deforestados, la casi inexistente necesidad de utilizar herramientas y técnicas sofisticadas de cultivo, el escaso laboreo de la tierra y los elevados rendimientos por unidad de superficie. Suscitada a finales de la década de 1930, la crisis del cultivo de yerba mate coadyuvó a la consolidación del tabaco en Misiones: la creación en 1936, por parte del Estado nacional, de la Comisión Reguladora de la Yerba Mate, impuso rígidos cupos de siembra y cosecha a ese cultivo, de ahí que gran parte de las tierras otrora plantadas con yerba fueron destinadas a sustentar la expansión del tabaco. No obstante, a mediados del siglo XX el tabaco ya no representaba el papel central de antaño, debido al costo del flete, la irregularidad del transporte fluvial, las contingencias climáticas, los múltiples cuidados que requería su producción y la asimétrica relación con los acopiadores. Su permanencia obedecía a su condición de único producto que los campesinos podían vender al contado, y así adquirir las mercancías que no se producían en la chacra -insumos, herramientas de labranza, calzado, prendas de vestir-, preservar la 'cuenta corriente' obtenida en el almacén y cancelar las deudas de capital adelantado contraídas en cada ciclo agrícola con las empresas.

Si bien a mediados del siglo XX el tabaco aún se destinaba, en Argentina, casi exclusi- vamente al consumo interno, en el resto de América Latina ya se había convertido en un típico producto de exportación; eso explica la sistemática estrategia de internacionalización y transnacionalización desplegada a partir de la década de 1960 por las grandes compañías cigarreras como respuesta a cierta saturación de la demanda, las campañas antitabaco, las restricciones impuestas a la publicidad, las crecientes campañas impositivas en los países capitalistas más industrializados, la imperiosa necesidad de encontrar en el extranjero nuevas fuentes baratas de tabaco en hoja -en virtud de los crecientes costos de producción de la materia prima en Estados Unidos y Europa-, y la imposición de un patrón de consumo ligado al cigarrillo rubio americano como producto de consumo internacional por excelencia: todo ello condujo a las empresas a expandir sus actividades en la periferia del sistema, especialmente en México, Brasil y Argentina, agudizando la internacionalización de sus procesos productivos y la integración vertical de la agricultura (Teubal, 1995). Si bien la actuación de agentes extralocales había sido relativamente frecuente entre la postguerra y la década de 1960, a partir del decenio de 1970 estos actores adquirieron inusitada relevancia (Slutzky, 2011; Rofman et al., 2008). Si hasta entonces solo una empresa cigarrera de Argentina (la Compañía Nobleza de Tabacos) era subsidiaria de la British American Tobacco, entre 1966 y 1968 se produjo la absoluta desnacionalización de la industria del cigarrillo; Massalin y Velasco fue adquirida por Philip Morris, Manufacturas Piccardo pasó a ser parcialmente controlada por Ligget \& Myers, y las Manufactureras de Tabacos Particulares e Imparciales fueron absorbidas por la alemana Reemtsma Cigaretten Fabriken (Teubal, 1995).

Surgido transitoriamente en 1967, el Fondo Tecnológico del Tabaco -posteriormente renombrado Fondo Especial del Tabaco (FET)-, cobró a partir de 1972 carácter permanente, convirtiéndose en el eje estructural de la política tabacalera argentina. Orientado a mejorar los ingresos de los productores y alentar su diversificación productiva, el FET desde entonces se financia a partir de impuestos al consumidor $-7 \%$ del precio de venta al público de cada paquete de cigarrillos, un adicional fijo de $\$ 0,00272$ por cada paquete de 20 unidades, 
y otro adicional del 0,35\%, que financia a las obras sociales del sector-: así pues, el precio de la producción primaria pasó a componerse del precio de acopio pagado por dealers, cooperativas e industrias, y un precio pagado por el Estado, que contempla un sobreprecio variable -que no puede superar el $40 \%$ del precio de acopio- y un adicional de emergencia -que no puede superar el $50 \%$ del sobreprecio, y se orienta a mitigar problemas sociales y económicos derivados del régimen de tenencia de la tierra-. El $80 \%$ de la recaudación del FET es transferido a las provincias productoras para subsidiar a los productores e implementar planes y seguros contra el granizo; el $20 \%$ remanente queda en manos del Estado nacional, que utiliza una parte para contribuir al mejoramiento de la calidad de la producción y mitigar los problemas económicos y sociales de las áreas tabacaleras.

Sin embargo, y a raíz del incremento de las ventas del cigarrillo rubio de tipo norteamericano -el llamado american blend, a base de las variedades Burley, Virginia y Oriental-, la agudización del fenómeno de la concentración empresarial -Nobleza y Piccardo se fusionaron en 1978-, la modernización industrial del sector -surgieron nuevas plantas con modernas instalaciones, que permitieron aumentar la productividad de 4.000 cigarrillos/minuto a 6.000 unidades/minuto-, y la aparición de nuevas marcas -orientadas sobre todo hacia el consumo de las capas sociales con mayores ingresos-, la integración vertical de la industria tabacalera aumentó durante la década de 1980 (Teubal, 1995). Misiones, respondiendo a la estrategia exportadora de British American Tobacco y Philip Morris, experimentó entre 1979 y 1986 una significativa expansión del tabaco Burley -'curado al aire', con un mínimo control artificial de la humedad, y requerimientos técnicos (escala de explotación, capacitación de los productores, nivel de tecnificación, necesidad de trabajo asalariado) mucho menores que la variedad Virginia cultivada en Jujuy y Salta-. Sustentada en diversos factores -suelos y climas propicios para obtener un tabaco con mayor tenor de nicotina en relación al tucumano; estructura agrícola sustentada en el trabajo familiar con menor riesgo empresario para los acopiadores; rápida asimilación de técnicas de cultivo por parte de los productores; y organización sindical bastante menos radicalizada que la tucumana (Bertoni \& Gras, 1994; Domínguez, 1995)-, la elevada productividad espacial del tabaco misionero en cuanto a su inserción en la división internacional del trabajo se basa también en la existencia de un tejido socioproductivo extremadamente propicio a la difusión de la agricultura bajo contrato y a la subsunción del trabajo familiar por parte de los intereses agroindustriales.

Obedeciendo a la apertura de nuevos mercados -Europa oriental, por ejemplo-, la reorientación de la producción tabacalera argentina hacia la exportación permitió a los dealers transnacionales adquirir la potestad de establecer las calidades y mezclas requeridas mediante acuerdos gracias a los cuales se aseguraban la compra de la producción antes de que esta se realizara, e incluso financiaban la adquisición y difusión de tecnología (García, 2011); así pues, esos agentes estrecharon aún más su relación con el sector acopiador (Gras, 1997) a través de contratos agroindustriales primero, y vía integración vertical por propiedad después: para responder a las exigencias del mercado mundial y cumplir los pactos suscritos con los dealers, los acopiadores, a su vez, se vieron obligados a imponer el modelo de agricultura contractual al productor. Si bien surgieron, en ese contexto, algunas 'cooperativas tabacaleras', estas le disputaron a las cigarreras el mercado exportador, en vez de proteger a sus asociados de las estrategias de acumulación de los dealers (García, 2011). El pequeño productor tabacalero misionero acabó, pues, subordinándose por completo a los intereses industriales y comerciales, perdiendo buena parte de su autonomía de antaño; esto ha derivado en un aumento de su pobreza relativa, que lo obliga a diseñar constantemente nuevas estrategias de supervivencia (Teubal, 1995), no solo merced al proceso explicado previamente, sino también gracias al discrecional manejo de los recursos del Fondo Especial del Tabaco, devenidos más en subsidios para las grandes empresas que en una ayuda efectiva para garantizar la reproducción social de los actores más débiles del circuito. 


\section{Orden global, campesinado y tabaco en Misiones (1990- 2012): reestructuración exportadora, hegemonía agroindustrial-comercial y crisis socioambiental}

Oriunda de los centros de poder del sistema capitalista, la ideología neoliberal acentuó, a partir de la última década del siglo XX, la crisis estructural de los Estados nacionales latinoamericanos; presentando al mercado mundial y a la gestión privada como "panaceas", renovando el mito de la "mano invisible' y condenando la intervención gubernamental en la economía doméstica, la 'mano invisible' se convirtió en un mecanismo de dominación que instauró en países y lugares la mentada fábula de la desregulación, 'sugiriendo' a estos confiar en el capital extranjero concentrado los aspectos fundamentales del proceso modernizador. Siempre de la mano de una métrica burocrática mercantilizada, y de una métrica mercantil desenfrenada, el Estado pasó a brindar protección pública a los ricos, y al mismo tiempo, a someter a los pobres a la disciplina del mercado (Borón, 1997). Orientado a conciliar las estrategias de acumulación de los grupos económicos nacionales diversificados y los capitales extranjeros -liberalización de las tasas de interés, apertura comercial y financiera, estabilización y anclaje nominal del tipo de cambio, 'desregulación' del mercado interno, enajenación de los monopolios estatales productores de bienes y servicios (ventas de activos, concesiones, licencias)-, el ajuste estructural impuesto por el Consenso de Washington preconizó abiertamente el desmantelamiento de casi todos los mecanismos de regulación pública de la acumulación del capital en América Latina, marcando un verdadero punto de inflexión o ruptura en la evolución de la economía y el territorio argentinos.

El neoliberalismo agudizó la metamorfosis del campo argentino, a escala tanto nacional como regional. Ningún otro sector de la economía argentina fue, de hecho, tan abruptamente sometido a los vaivenes del mercado mundial como el agropecuario. El campo fue instado a incorporar con renovados bríos un know-how homogéneo y globalizado (Silvei- ra, 1999), y esto alentó la profundización de la integración vertical de los circuitos productivos, la mayor difusión de la agricultura bajo contrato, la penetración del 'supermercadismo', el desmantelamiento de los entes regulatorios destinados a evitar o mitigar la crisis de sobreproducción, y la sistemática concentración de tierras y producción en manos de poderosos terratenientes y grandes complejos agroindustriales extranjeros $y$ vernáculos; así pues, el espacio nacional fue reorganizado para servir a una racionalidad que considera 'residual' al mercado interno y al consumo doméstico: por eso, desde entonces la Argentina drena al exterior el $90 \%$ de su producción agropecuaria.

Si bien el tabaco no constituye una producción hegemónica a nivel nacional, ciertamente ha gozado, en el marco de los cambios estructurales mencionados, de cierto auge: entre 1989 y 2005, su superficie creció un $79,4 \%$, las cosechas aumentaron un 138,1\% y los rendimientos hicieron lo propio en un 35,5\% (Argentina, 2006) (Cuadro No 1); y así, en un mercado dominado por cuatro empresas -las firmas transnacionales Philip Morris, British American Tobacco y Japan Tobacco, y la empresa estatal China National Tobaccoy ocho países -China, India, Brasil, Estados Unidos, Indonesia, Turquía, Malawi y Zimbabwe-, la Argentina pasó a dar cuenta del $2 \%$ de la producción mundial y del $4 \%$ de comercio internacional.

En Misiones, el nuevo modelo de acumulación reinante a nivel nacional determinó que, a partir de la segunda mitad de la década de 1990, los usos agrícolas del territorio local mutaran, sufriendo una intensa reestructuración: por un lado, algunos cultivos perennes (yerba mate, té, tung, cítricos) se sumieron en una profunda crisis estructural, a raíz de la eliminación de los cupos de siembra y cosecha, la consiguiente sobreproducción, la caída de los precios, la desaparición de los entes regulatorios que legislaban el intercambio entre los productores primarios y el sector agroindustrial, y las condiciones ambientales adversas para su desenvolvimiento -suelos pedregosos de elevada pendiente-, lo cual redundó en cierto distanciamiento respecto al clásico patrón agrario de capitalización hasta entonces vigente en la provincia; por otro lado, la valorización inmobiliaria de las tie- 
Cuadro $\mathrm{N}^{\circ} 1$

Indicadores seleccionados del sector tabacalero. Total del país, período 1989-2005

\begin{tabular}{|l|r|r|r|r|r|r|}
\hline Año & $\begin{array}{c}\text { Superficie } \\
\text { tabaco }(\mathrm{ha})\end{array}$ & \multicolumn{1}{c|}{$\begin{array}{c}\text { Producción } \\
\text { tabaco }(\mathrm{kg})\end{array}$} & $\begin{array}{c}\text { Rendimiento } \\
(\mathrm{kg} / \mathrm{ha})\end{array}$ & $\begin{array}{c}\text { Superficie } \\
\text { Burley }(\mathrm{ha})\end{array}$ & $\begin{array}{c}\text { Producción } \\
\text { Burley }(\mathrm{kg})\end{array}$ & $\begin{array}{c}\text { Rendimiento } \\
(\mathrm{kg} / \mathrm{ha})\end{array}$ \\
\hline 1989 & 51.035 & 67.633 .827 & 1.430 & 14.790 & 17.450 .906 & 1.431 \\
1997 & 84.454 & 116.509 .702 & 1.513 & 23.697 & 36.010 .958 & 1.625 \\
2000 & 59.647 & 98.110 .172 & 1.726 & 24.074 & 35.779 .851 & 1.508 \\
2005 & 91.559 & 161.063 .709 & 1.937 & 40.881 & 60.239 .922 & 1.690 \\
\hline
\end{tabular}

Fuente: Elaboración propia en base a Argentina (2006).

rras catalizó la disputa por la apropiación del territorio local entre dos modelos productivos diferenciados: la forestación a gran escala integrada a la industria celulosa y maderera, y la pequeña producción agrícola ligada al autoconsumo y el mercado, estructurada en torno al tabaco como principal cultivo de renta (García, 2011). Emblemas históricos de la tradicional especialización silvo-agrícola de Misiones, ambas producciones se constituirían en pilares de la agricultura científica globalizada local.

El tabaco pasó a concentrar, en 2002, el $3,6 \%$ de la superficie provincial implantada -25.627 ha- y el $40,4 \%$ de las explotaciones agropecuarias -11.290 unidades- (Argentina, 2005) (Cuadro No 2); se cultivaba en siete de los diecisiete departamentos de la provincia, arraigándose en la franja territorial existente entre la Ruta Nacional 14 y el río Uruguay. El auge ganado por el tabaco desde finales del siglo XX en algunos de esos distritos explica que, pese a que la cantidad general de explotaciones agropecuarias provinciales permaneció casi constante entre 1988 y 2002, en los departamentos de frontera el número de unidades productivas se hava incrementado ostensiblemente -Guaraní (de 3.549 a 4.600), General Belgrano (de 1.302 a 2.384) y 25 de Mayo (de 2.007 a 2.255) (Slutzky, 2011)-, dinamizados por una expansión de la frontera agrícola ligada al surgimiento de nuevos frentes tabacaleros y la consolidación de los cinturones preexistentes.

Solidaridades tejidas entre la rápida aceptación del Burley local en el mercado internacional -en virtud de su condición de producto artesanal-, las excepcionales aptitudes climáticas para su cultivo, la producción primaria basada esencialmente en el trabajo familiar, y la consolidación de la agricultura contractual, afianzaron e incrementaron la productividad espacial de Misiones como principal área tabacalera del país: a comienzos del siglo XXI, reunía el 38,2\% -20.620 hectáreas- de la superficie implantada, el $30,3 \%-27.093 .216$ toneladas- de la producción global a nivel nacional, y al 69,3\% -18.092 - de los productores (Argentina, 2005, 2006) (Cuadro No 3); junto a las principales provincias tabacaleras del noroeste argentino -Jujuy $(32,8 \%)$ y Salta $(23,7 \%)-$, daba cuenta del $91 \%$ de las cosechas -el remanente correspondía a la participación marginal de Corrientes, Tucumán, Catamarca y Chaco-, e incrementó considerablemente $(65,1 \%)$ su producción tabacalera entre 1990 y 2005 , superando los guarismos de Jujuy $(25,9 \%)$ y Tucumán $(-28,3 \%)$-ese aumento solo fue rebasado por Salta $(98,1 \%)$ - (Argentina, 2006). Se observa, asimismo, el afianzamiento y expansión del modelo tabacalero de exportación, que privilegia el cultivo de Burley en detrimento de otras variedades: si en 1990 representaba el $74,9 \%$ de la superficie provincial plantada con tabaco y el $79,2 \%$ de la producción, en 2005 daba cuenta del $92,8 \%$ y del $95,1 \%$, respectivamente, como resultado del significativo aumento de su área $(176,4 \%)$ y sus cosechas $(77,5 \%)$; a su vez, Misiones pasó de acaparar, en 1998, el $62,6 \%$ de las cosechas de tabaco Burley, a concentrar en 2005 el 82,7\% (Argentina, 2006).

La nueva lógica exportadora se instaló en el territorio local como resultado de las estrategias de concentración del capital e integración vertical del eslabón agroindustrial/ comercial desplegadas por las principales fir- 
Cuadro $\mathrm{N}^{\circ} 2$

Datos generales del sector agropecuario. Provincia de Misiones, año 2002

\begin{tabular}{|l|r|}
\hline Superficie total (ha) & 2.067 .805 \\
Superficie cultivada (ha) & 718.208 \\
Superficie plantada con tabaco (ha) & 25.627 \\
Explotaciones agropecuarias & 27.955 \\
Explotaciones tabacaleras & 11.290 \\
Unidades productivas menores a 15 ha/superficie (\%) & 29,2 \\
Unidades productivas menores a 15 ha/explotaciones agropecuarias (\%) & 32,4 \\
\hline
\end{tabular}

Fuente: Elaboración propia en base a Argentina (2005).

Cuadro $\mathrm{N}^{\circ} 3$

Indicadores seleccionados del sector tabacalero. Provincia de Misiones, período 1990-2005

\begin{tabular}{|l|r|r|r|r|r|r|}
\hline Año & $\begin{array}{c}\text { Superficie } \\
\text { tabaco }(\mathrm{ha})\end{array}$ & $\begin{array}{c}\text { Producción } \\
\text { tabaco }(\mathrm{kg})\end{array}$ & $\begin{array}{c}\text { Rendimiento } \\
(\mathrm{kg} / \mathrm{ha})\end{array}$ & $\begin{array}{c}\text { Superficie } \\
\text { Burley }(\mathrm{ha})\end{array}$ & $\begin{array}{c}\text { Producción } \\
\text { Burley }(\mathrm{kg})\end{array}$ & $\begin{array}{c}\text { Rendimiento } \\
(\mathrm{kg} / \mathrm{ha})\end{array}$ \\
\hline 1990 & 15.016 & 19.493 .969 & 1.427 & 11.252 & 15.433 .108 & 1.507 \\
1997 & 21.304 & 32.796 .892 & 1.620 & 16.000 & 26.050 .714 & 1.714 \\
2000 & 20.756 & 27.093 .216 & 1.332 & 17.489 & 24.830 .076 & 1.441 \\
2005 & 35.232 & 52.388 .944 & 1.599 & 32.692 & 60.239 .922 & 1.637 \\
\hline
\end{tabular}

Fuente: Elaboración propia en base a Argentina (2006).

mas transnacionales del sector tabacalero. No sin altibajos, desde la década de 1990 hasta la actualidad seis empresas integran el sector acopiador local: la Cooperativa Tabacalera de Misiones (CTM); la Comercial Industria Misionera Argentina (CIMA); la Cooperativa Tabacalera San Vicente (COTAVI); Tabacos Norte; Bonpland Leaf (BLASA); y Alliance One (producto de la fusión internacional entre Standard y Dimon); a las compañías citadas se añaden algunas firmas brasileñas que realizan ventas directas y pagan al contado. No obstante, Rofman et al. (2008) explican que, en lo que respecta a la vinculación acopiador-productor, esta pluralidad de compañías no es tal: las seis empresas funcionan como razón social, pero en realidad, las que efectivamente se relacionan con los productores son CTM, Bonpland, CIMA y TN; paralelamente, García (2011) señala que la aparente diversidad de razones sociales enmascara la concentración económica del sector: la CTM, por ejemplo, que posee como clientes a Alliance One y a Philip Morris, se vale de recursos del Fondo Especial del
Tabaco para controlar a CIMA y BLASA; a su vez, esta última es una filial de Universal Leaf, quien explota Tabacos Norte junto a Alliance One y Massalin Particulares -filial argentina de la norteamericana Philip Morris, y minoritariamente integrada por la alemana Reemsma Cigaretten Fabriken GMBH-. Tanto CTM como Tabacos Norte se encuentran relacionadas -y en este último caso, integradas comercialmente- con los principales dealers y cigarreras de Occidente (García, 2010).

Las empresas acopiadoras/exportadoras hallaron, en Misiones -y también en el sudeste brasileño-, un contexto socioterritorial fértil para desplegar sus estrategias globales de acumulación, afianzar el modelo exportador en ciernes, desarrollar la concentración del capital y la integración vertical, y organizar la cadena agroindustrial del tabaco exclusivamente en función de sus propios intereses. Según Slutzky (2011), factores como una agricultura basada en la producción a pequeña escala, la gran concentración empresarial previa de los eslabones de comercialización 
e industrialización de la cadena, una población activa demandante de un ingreso monetario en su mayor parte obtenido del tabaco, unidades económicas de subsistencia de carácter exclusivamente familiar, la preexistencia del modelo de agricultura bajo contrato, y alternativas productivas -como la yerbamate- que requerían inversiones significativas con plazos de recupero muy dilatados, volcaron masivamente al campesinado hacia el cultivo de Burley en tanto que única opción viable de reproducción económica y social. Como la producción vía trabajo asalariado implica mayores costos, y los agricultores subsisten tan solo gracias a la autoexplotación de su fuerza de trabajo familiar -cuyo costo es desestimado por las empresas, que abonan un precio considerablemente menor al que deberían pagar si adquirieran el tabaco a explotaciones con fuerza laboral asalariada-, las firmas transnacionales impusieron fácilmente sus condiciones al campesinado que, ante la ausencia de alternativas productivas viables, se volcó masivamente al Burley: lucrando tanto con el precio del acopio pagado en relación al precio de venta internacional $-y / o$ el precio del cigarrillo- como con el valor de los insumos adelantados al productor y los costos de financiamiento y asistencia técnica-, los acopiadores extraen plusvalía del productor, desconociendo el valor del trabajo de su familia y apropiándose de la renta del suelo (García, 2011). Se impone, en el territorio local, una racionalidad vertical, jerárquica, que desestructura las lógicas horizontales intrínsecas a la reproducción del cotidiano campesino.

La agricultura tecnificada y cientifizada asociada a la revolución biotecnológica global suscitada a finales del siglo XX tampoco ha sido ajena, por cierto, al surgimiento $y$ consolidación del Ilamado boom del Burley misionero. Originadas en los experimentos de laboratorios farmacéuticos, firmas biotecnológicas y fabricantes de agrotóxicos, las semillas genéticamente modificadas son, indiscutiblemente, la base y el ariete del actual proceso de crono-expansión de la frontera agropecuaria. Inocentes solo en apariencia, esas simientes esconden dentro de sí una nueva división social y territorial del trabajo, portando en sus entrañas un complejo y eficaz circuito de mecanismos de subordinación y dependencia -sistemas de patentes biotec- nológicas, normas de sanidad y calidad, sistemas técnico-organizacionales (agroquímicos, maquinarias, modalidades de explotación, asistencia financiera) - que teje intrincados nexos entre la irrupción de los capitales extraagrarios en la producción primaria, el auge de la ingeniería genética, la mayor especialización y extroversión de la producción, la creciente influencia de los bancos sobre la actividad agropecuaria, la concentración de la tierra y el vaciamiento demográfico rural.

Argentina no ha resultado impermeable, ciertamente, a esa racionalidad: la adopción del Protocolo de Cartagena sobre Seguridad Biológica y la suscripción a la Unión Internacional de Protección de Obtentores de Variedades le otorgó a la industria semillera extranjera la seguridad jurídica necesaria para convertir a nuestro país en el principal productor mundial de Organismos Genéticamente Modificados (OGM's) -18 millones de hectáreas-, después de los Estados Unidos -55 millones de hectáreas- (ISAAA, 2007). En el caso puntual del tabaco, los intereses de las firmas globales de biotecnología y las semilleras transnacionales por conquistar mercados fueron complementados por el influjo de otras instancias globales de regulación, como las continuas y sistemáticas presiones de la Organización Mundial de la Salud para que la Argentina ratificara el Convenio Marco para el Control del Tabaco, las nuevas leyes de restricción de consumo vigentes en los países desarrollados -que estipulan que el consumidor debe ser informado respecto de los tenores de nicotina y otros alcaloides que contiene la materia prima con la cual fue elaborado el cigarrillo-, y la imposición de variedades previamente aprobadas desde el punto de vista organoléptico (sabor e impacto) por distintos paneles internacionales de fumadores. Las nuevas normas del sector -verdaderas verticalidades- reestructuraron el territorio local en función de las políticas de los países consumidores y las estrategias de acumulación de las transnacionales.

Obedientes a la nueva racionalidad, los nuevos paquetes tecnológicos han implicado tanto la difusión de semillas resistentes a herbicidas y adversidades climáticas, la reducción del contenido de nicotina, y la incorporación, en su secuencia genética, de factores de transcripción y mutantes de arroz, y de an- 
ticuerpos de ratón (CONABIA, 2006), como el habitual $-y$ obligatorio- uso de diversos agrotóxicos, entre ellos el glifosato de amonio, herbicida de acción global cuyo auge se debe, sobre todo, al denominado 'boom de la soja transgénica', y en menor medida, a la ingeniería genética desplegada en otros cultivos de menor importancia relativa, como el maíz, el arroz, el girasol, el algodón, la caña de azúcar y el tabaco (CONABIA, 2006; Gómez Lende, 2006). Si bien el discurso dominante arguye que los OGM's demandan la aplicación de menores cantidades de agrotóxicos que las variedades convencionales, la realidad demuestra exactamente lo contrario: el Burley requiere la aplicación sistemática de numerosos herbicidas -entre ellos, el ya mencionado glifosato de amonio, clomazone, napropamida, trifluralina, pendimetalin y metolacloro-, insecticidas, nematicidas y acaricidas -acefato, clorpirifos, fenamifos, carbofuranos y endosulfatos, deltametrina, oxicloruro de cobre y Bacillus Thuringiensis-, fungicidas -sulfato de zinc- $y$ alcoholes grasos (Dutra, 2010); diametralmente diferente de la observada en Salta o Tucumán, donde la producción tabacalera suele ser orgánica, esta situación es endémica de Misiones (Agüero, 2009). Misiones exhibe, por consiguiente, mayor permeabilidad relativa al paradigma de la agricultura globalizada, volviéndose más 'racional', adquiriendo mayor productividad espacial que otras áreas tabacaleras, desarrollando una crono-expansión de la frontera agropecuaria basada en la propagación de los OGM's y los agrotóxicos de Monsanto, Du Pont y Bayer, y funcional a los intereses y estrategias de Philip Morris y Carolina Leaf Tobacco.

Impetuosa, la 'quimificación' de la agricultura misionera se instaló y propagó rápidamente entre el campesinado local, so pena de, caso contrario, no lograr la inserción de su producción en el mercado. García (2010, 2011) explica que, al inicio de cada campaña, el agricultor -que debe estar inscripto como monotributista en la Administración Federal de Ingresos Públicos (AFIP)- suscribe un contrato de producción con una empresa acopiadora, en el cual se compromete a satisfacer un determinado cupo de determinada cantidad y calidad de tabaco, y a adquirir el paquete tecnológico -agroquímicos, semillas, asistencia técnica- requerido para tal fin, cuyo valor será descontado al momento del acopio. Surge, así, un compromiso de producción y un endeudamiento, vinculado a un mercado cautivo y oligopólico, en el cual el tabacalero resigna su autonomía productiva en función de requerimientos externos que escapan a su control.

Orientadas tanto a consolidar su posición hegemónica como a disciplinar al campesinado, otra estrategia de las tabacaleras consiste en rechazar en las bocas de acopio la producción obtenida con 'semillas caseras' (sin denominación de origen) importadas desde Brasil, y la vez penalizan a los agricultores que, atraídos por la diferencia cambiaria existente con el vecino país y los precios más elevados -en 2008, \$9,00/kg contra $\$ 5,75 /$ $\mathrm{kg}$-, remesan materia prima al mercado carioca; expresamente prohibido, el escurrimiento de hoja de tabaco hacia Brasil es, desde la perspectiva del acopiador, una práctica de contrabando, y quienes incurren en dicha infracción son sindicados como 'malos productores' y excluidos del circuito (García, 2011). Es el imperio de las normas de las firmas transnacionales sobre los espacios agrícolas y los usos del territorio local.

Surgidos al calor de la comunión, en el territorio, de la técnica -la biotecnología y ingeniería genética- y la política -las normas globales-, modernos sistemas productivos hicieron su aparición para afianzar el nuevo modelo de agricultura tecnificada y cientifizada; tradicionalmente, los almácigos de tabaco eran plantados en tierra, luego de la desinfección y esterilización de los suelos con bromuro de metilo, químico gaseoso cuyo uso fue prohibido en los Estados Unidos en 1976, pero que aún es frecuentemente utilizado en los países periféricos. No obstante, la creciente preocupación ambiental mundial en torno al 'calentamiento global' o 'efecto invernadero' condujo, en los últimos años, a la rúbrica, por parte de numerosos países -entre ellos, la Argentina-, de diversos tratados internacionales que instan a abandonar el uso del citado insumo, toda vez que se lo considera perjudicial para la preservación de la capa de ozono (Cáceres, 2009). Como respuesta a la imposibilidad de continuar con el desarrollo de prácticas agrícolas pretéritas, surgieron plantaciones de tabaco desarrolladas bajo el 'sistema floating', o hidroponía, 
que consiste en la disposición de almácigos sobre bandejas de telgopor flotantes, alimentados con agua y sin contacto con el suelo; pionera, Misiones fue la primera provincia en aplicarlo exitosamente (Cáceres, 2009). El sector tabacalero local halla, en la difusión de la hidroponía, una nueva forma de cronoexpansión de la frontera agropecuaria.

Obediente a los cambios suscitados en la racionalidad ambiental global, la nueva lógica productiva no ha sido ajena, empero, a los intereses de las transnacionales tabacaleras; aunque estas no han sido las mentoras de esa transformación tecnológica, sí han fomentado su adopción entre el campesinado, presentándola como la única opción viable y eficaz: son los dealers, los acopiadores y las agroindustrias quienes, en última instancia, han elegido promover esta alternativa por sobre otras opciones tecnológicas actualmente disponibles en el mercado, en virtud de la elevada eficiencia de la hidroponía, su gran capacidad para producir plantines de gran calidad, la facilidad para la estandarización del proceso en áreas de alta variabilidad ambiental, la posibilidad de incorporar mayores cantidades de insumos al proceso productivo $-y$ de ese modo controlar aún mejor (y más estrechamente) la extracción de excedentes a los agricultores familiares-, y su funcionalidad para establecer estrategias de selectividad y exclusión entre los productores -desechando a aquellos menos proclives a la innovación y menos capacitados para adoptar los paquetes tecnológicos de la agricultura industrial (Cáceres, 2009), y escogiendo a aquellos que, desde la óptica de los agentes hegemónicos, son más permeables al nuevo modelo-.

Siempre retroalimentándose, la hegemonía agroindustrial y la desestructuración y subordinación del campesinado aparecen como caras de una misma moneda. Obligados a reestructurarse rápidamente - sin acompañamiento ni asesoramiento técnico-, los agricultores familiares son segmentados según sus diferentes niveles de racionalidad -esto es, en cuanto a su aptitud y actitud respecto de la adopción de la lógica dominante-, y se tornan dependientes de la adquisición de un know-how que afianza su subordinación a los intereses agroindustriales, que consiguen hacer más lucrativos sus contratos con los campesinos, adelantándoles capital para la adquisición de la totalidad de los insumos necesarios para la implementación del moderno paradigma productivo. Obstando el aumento de la necesidad de insumos externos, la hidroponía supone un arduo e inédito desafío para campesinos de nivel educativo bajo, habituados al uso de paleo-tecnologías como el fuego y la tracción a sangre (Cáceres, 2004), y que manejan explotaciones de muy escaso (o nulo) grado de capitalización: de hecho, la principal herramienta de trabajo del $90 \%$ de los productores tabacaleros es la yunta de bueyes, en tanto que el $10 \%$ restante utiliza tractores cuya antigüedad promedio ronda los 26 años (Gortari, 2007).

Solidaridades entabladas entre la atomización de la oferta de la materia prima y la oligopolización de la demanda coadyuvan, ciertamente, al afianzamiento de este modelo de hegemonía agroindustrial y subordinación campesina. Solo cuatro empresas daban cuenta, en 2007, del 57\% del acopio: Alliance One (19\%), Universal Leaf Tabacos SA $(17 \%)$, Massalin Particulares (17\%) y Bonpland Leaf $(4 \%)$; el resto de la producción era absorbido por la Cooperativa Tabacalera de Misiones (36\%) y a CIMA (7\%) (García, 2010). Si se considera, más allá de las razones sociales, la propiedad del capital de las firmas citadas, Philip Morris, Alliance One y Universal Leaf se apoderaban de la totalidad de las cosechas. En el sector industrial no se verificaba una concentración menor: según el Censo Económico Nacional 2004, Nobleza Piccardo -filial de la British American Tobacco- y Massalin Particulares eran, junto a otras dos firmas, responsables por el $73,5 \%$ del valor bruto de producción de cigarrillos del país (Argentina, 2007). Todas las empresas acopiadoras se articulan, asimismo, al mercado mundial, a través de los flujos de exportación; esto es alentado por el Estado nacional, quien les reintegra las retenciones o derechos de exportación, e incluso otorga a CTM subsidios públicos directos.

Orientadas, sobre todo, a Europa -Bélgica, Alemania, Holanda, Francia, Inglaterra, Rusia, Portugal- y América del Norte -Estados Unidos, Canadá- y, en menor medida, a Brasil, Paraguay, Uruguay y Filipinas, las exportaciones fueron, en principio, erráticas, a raíz de la acumulación de grandes stocks por parte de los dealers internacionales conforme 
a las reiteradas oscilaciones de los precios y a las políticas de incentivos/restricciones formuladas por los principales países productores y consumidores: así pues, la crisis de sobreproducción de 1993 -vinculada al ingreso al mercado de los países de Europa Oriental- dio lugar, por ejemplo, a un ciclo de auge durante el subperíodo 1994-1997, lapso en el cual las exportaciones argentinas crecieron un $40 \%$; y durante el bienio 1998 1999, el valor y el volumen de las remesas de tabaco cayó un $30 \%$ y $12 \%$, respectivamente, como resultado tanto de los aumentos impositivos y los elevados costos derivados de los litigios relacionados con el consumo de cigarrillos en los principales países importadores, cuanto de la devaluación del real y la recuperación de ese cultivo en Brasil. No obstante, posteriormente el sesgo exportador se consolidó: en 2006 las exportaciones tabacaleras argentinas superaron la barrera histórica de los 103.348.267 kg, generando divisas por U\$S 252.121.009, y explicando entre el $15 \%$ y el $20 \%$ del comercio exterior misionero (Argentina, 2006). Los envíos al exterior se incrementaron un $75 \%$ entre 1996 y 2009 -pasaron de 54 a 99 millones de $\mathrm{kg}-$, y aumentaron su peso relativo sobre la producción-del $73 \%$ en 1995 al 81,6\% en 2008-, acentuando la orientación exportadora del Burley misionero, pues una parte de la producción que históricamente se consumía en el país fue drenada a los mercados internacionales (Slutzky, 2011); paralelamente, la demanda interna declinó: el consumo aparente -paquetes de cigarrillos per cápita/añoera, en 2010, similar al de mediados del siglo XX (Argentina, 2012).

\section{El desorden local: la problemática ambiental, sanitaria y social del campesinado}

Orden global suele ser, por lo general, sinónimo de desorden local; Santos \& Silveira (2001) explican que, demasiado a menudo, los usos modernos del territorio son, de hecho, racionales únicamente para los agentes que se benefician con ese modelo de organización espacial, deviniendo absolutamente irracionales para todos los demás actores. Si se observan sus implicancias más nefastas e inicuas, el estudio de caso aquí expuesto no parece constituir, ciertamente, una excepción a esa regla: el inusitado brío exportador con que el Burley misionero se inserta en el mercado mundial acarrea graves costos locales en el plano ambiental y social, derivados tanto de los procesos históricos de dominación cultural y reproducción de la desigualdad social (Agüero, 2009) cuanto de la inserción de los tabacaleros en una división internacional del trabajo que, en virtud de los modos y mecanismos imperantes de vinculación con las agroindustrias, tiende a reproducir sus -ya de por sí harto- difíciles condiciones materiales de existencia (García, 2011). Su grave perjuicio a la salud de los consumidores, la remesa de la mayor parte de la producción al exterior, la contaminación ambiental, el impacto sobre la salud de los agricultores y sus familias, y el agravamiento de la preexistente crisis social del campesinado, convierten a este cultivo en lo que Marx (1980) llamó una 'producción innecesaria', que solo consigue prosperar gracias a la perpetuación y profundización de la miseria material de los agentes más débiles del circuito, y a expensas de los intereses de la sociedad local.

El impacto ambiental del nuevo modelo tabacalero es nefasto: después de cada campaña, los agroquímicos aplicados persisten en los suelos durante no menos de una década, despojando de fertilidad de la tierra -anulan la acción de microorganismos vitales para la descomposición de materia orgánica y la incorporación de nutrientes al suelo-, generando resistencia en las plagas -lo cual obliga a incrementar las dosis y/o suplantarlos por productos aún más peligrosos-, desarticulando el equilibrio de las cadenas tróficas -exterminan a organismos acuáticos, peces, aves, mamíferos y enemigos naturales de ciertas plagas-, empobreciendo la biodiversidad y contaminando las aguas superficiales y subterráneas, el suelo y el aire -parte de los envases de agroquímicos es enterrada, y el resto es incinerado, liberando dioxinas cuya toxicidad rebasa ampliamente a la del agroquímico original- (Agüero, 2009; Páez, 2008; Dutra, 2010). No es extraño entonces que, a raíz de la combinación de la toxicidad de esos productos, la ignorancia de los campesinos -buena parte de los cuales es analfabeta-y el afán de lucro de los agentes dominantes del circuito, un universo de 67.000 tabacaleros 
-esto es, los productores y su grupo familiar- se halle en Misiones diariamente sometido, por manipulación laboral y/o exposición ambiental, a los riesgos derivados del uso intensivo de agrotóxicos; esa grave problemática es exacerbada, asimismo, por diversos factores, entre los cuales sobresalen: la corta distancia existente entre los cultivos y los hogares, y entre las plantaciones de tabaco y el ganado, las hortalizas y los frutales; la utilización de fuerza de trabajo esencialmente familiar; la gran dedicación intensiva que requiere el cultivo; la dinámica de utilización de los agroquímicos; y, sobre todo, su principal método de aplicación -manual, con mochila pulverizadora- (Dutra, 2010).

Obviamente, las solidaridades entabladas entre el bajo nivel de instrucción de los productores y las estrategias de integración contractual desplegadas por agroindustrias y acopiadores son funcionales a la reproducción social y territorial de los costos sociales, ambientales y sanitarios del nuevo modelo tabacalero. El imaginario colectivo del campesinado se halla profundamente distorsionado en cuanto a la peligrosidad real de los agroquímicos para la salud humana, contando con datos que no son en modo alguno precisos, y a veces, ni siquiera correctos: la familiaridad y cotidianeidad del uso de agrotóxicos -aunadas a la falta de información y comprensión acerca de su lógica profunda de funcionamiento- conducen a que las intoxicaciones derivadas de la exposición a los mismos sean atribuidas solo a su verdadera causa cuando su gravedad detiene el proceso de trabajo o atenta directamente contra la vida del productor y/o su familia -en un exhaustivo trabajo de campo (Dutra, 2010), se constata que todos los colonos niegan haberse intoxicado con plaguicidas, a pesar de haber sufrido reiterados malestares, dolores de cabeza y vómitos inmediatamente después de las fumigaciones-; incluso algunos productores sostienen, en su sistema individual de creencias, la falaz idea de que el contacto prolongado con los agroquímicos acabará generando en sus organismos una suerte de 'inmunidad' que, a la postre, neutralizaría sus potenciales efectos adversos (Dutra, 2010). La ignorancia de los agricultores y sus familias es harto funcional a los intereses de las grandes tabacaleras, que delegan en aquellos no solo los riesgos económicos asociados a la producción primaria, sino que también les transfieren sus externalidades socioambientales más negativas; esto conduce a la formulación de estrategias que repercuten en eslabones aún más débiles del circuito: los productores que cuentan con cierta capacidad de ahorro no exponen a sus familias a las tareas de preparación y aplicación de plaguicidas, sino que contratan fuerza de trabajo asalariada para tal fin, estrategia que traslada el riesgo socioambiental a los peones, el sector más vulnerable y empobrecido de la población rural provincial (Dutra, 2010; Baranger \& Castiglioni, 2007).

Si se consideran sus implicancias sobre la salud de la población rural, el nuevo modelo tabacalero es, a todas luces, inicuo. Los agroquímicos utilizados son hipofílicos e hidrofóbicos -rechazan el tejido acuoso y se adhieren al tejido adiposo-; la exposición reiterada al glifosato de amonio provoca lesiones en glándulas salivales y el aparato gástrico, trastornos reproductivos, disrupciones hormonales, esterilidad masculina, abortos espontáneos, daños genéticos y carcinogénesis en los agricultores y sus familias, situación que se agrava en el caso de las madres en gestación y/o período de lactancia, puesto que los metaloides y metales pesados presentes tanto en el agrotóxico citado como en otros productos de igual peligrosidad acaban incorporándose al genoma materno, transfiriendo las disfunciones genéticas resultantes al feto y/o lactante: como resultado, entre la población infantil rural son comunes los casos de fisura labio-palatina, linfomas, leucemia, otros tipos de cáncer, afecciones respiratorias severas, malformaciones cardíacas y renales congénitas, epilepsia, trastornos metabólicos, ceguera, parálisis cerebral, retraso psicomotor, discapacidad intelectual, síndrome de Down y mutaciones genéticas. Se estima que, en Misiones, 5 de cada 1.000 niños nacen afectados de mielomeningocele, enfermedad caracterizada por graves malformaciones del sistema nervioso central -alumbramiento con la médula espinal abierta, lo cual implica el padecimiento de por vida de trastornos de los miembros inferiores e incontinencia urinaria y fecal- (Páez, 2008); de ahí que la tasa de mortalidad infantil de departamentos tabacaleros como General Belgrano (18,5 por mil) y 25 de Mayo (22,9 por mil) rebase la media provincial (16,6 por mil) (Slutzky, 2011). 
Quienes sobreviven a algunos de los trastornos mencionados acaban transmitiéndolos a sus descendientes, a raíz de la modificación del ADN; es por esa razón que, en 2011, unas 120 familias campesinas entablaron una millonaria demanda judicial contra las empresas Monsanto, Bayer, Du Pont, Philip Morris y Carolina Leaf Tobacco Company en el Tribunal del Condado de New Castle (Estados Unidos), en virtud de los graves perjuicios sociales, ambientales y sanitarios ocasionados por el uso intensivo de agrotóxicos sin la adecuada capacitación y asesoramiento técnico. No obstante, los agricultores misioneros continúan plantando tabaco, paradoja que, llevada al plano de la teoría social del riesgo propuesta por Beck (1993), demuestra que, cuando la amenaza visible de la muerte a manos del hambre y la amenaza invisible de la muerte por intoxicación entran en conflicto, demasiado a menudo triunfa la lucha librada contra la primera.

No faltan, empero, los discursos oficiales que procuran enmascarar la gravedad de la situación: la Comisión Técnica del Tabaco de la provincia de Misiones, por ejemplo, asegura que el uso de agroquímicos se redujo un $86 \%$ entre 2001 y 2011 -pasó de $8,50 \mathrm{~kg} /$ ha a $1,17 \mathrm{~kg} / \mathrm{ha}-($ COTTAPROM, 2012), y que los plaguicidas más peligrosos han sido reemplazados por productos de menor toxicidad. No obstante, la problemática socioambiental y sanitaria del sector tabacalero aún es insoluble. Sancionada en 1993, la 'Ley de Agrotóxicos' (2.980) prohíbe el uso de agrotóxicos que hayan dejado de ser utilizados en su país de origen o en países donde se haya demostrado sus perjuicios para la salud humana, pero no se cumple; por el contrario, es sistemáticamente avasallada por los intereses de las firmas globales de la biotecnología, las semilleras extranjeras, las empresas transnacionales del sector químico y, sobre todo, las grandes tabacaleras, que en sus contratos continúan exigiendo a los agricultores la compra y uso de sus paquetes tecnológicos como condición sine qua non para la adquisición de la producción.

Obstando la connivencia de un aparato burocrático refuncionalizado para servir a los intereses de las firmas globales, ¿qué otras razones podrían explicar que, a pesar de tratarse de un producto que ocasiona severos trastornos a la salud de productores y consumidores, y que es objeto, a nivel mundial, de sendas campañas destinadas a desalentar su consumo, el Estado nacional y provincial continúen permitiendo y apañando su desenvolvimiento? Quizás su generoso aporte al erario sea la respuesta: contabilizando los impuestos internos, el Impuesto al Valor Agregado, los gravámenes sobre las ventas y las contribuciones al Fondo Especial del Tabaco y el Fondo de Asistencia Social, el sector aporta al fisco 2.000 millones de dólares anuales, guarismo que representa aproximadamente el $4 \%$ de la recaudación tributaria nacional (Corradini et al., 2005). El Estado nacional se apodera del $90 \%$ del valor comercial de la producción; paralelamente, el tabaco posee un significativo impacto económico a nivel provincial -inyecta cada año 630 millones de pesos a la economía misionera (Agüero, 2009)-, de ahí que el actual modelo de agricultura de exportación sea acérrimamente defendido por la burocracia política local, a pesar de sus inicuas implicancias sobre el ambiente y la salud de la población. Todo lo anterior coadyuva, pues, a diseñar y reproducir, desde la esfera pública, una fábula o psicoesfera destinada a legitimar el modelo de modernización socioterritorial reinante en el medio rural.

Sin embargo, el 'efecto-derrame' propugnado desde el aparato estatal -especialmente a través de organismos como el Fondo Especial del Tabaco (FET) - es una falacia: de hecho, Agüero (2009) sugiere que el FET es el principal instrumento de dominación ideológica y cultural que opera sobre el campesinado misionero, pues inocula en su imaginario la falsa creencia de que el tabaco es una alternativa viable para prosperar y progresar; aunque los impuestos al cigarrillo constituyan, en teoría, un recurso tributario genuino -aportado por los fumadores y captado sin intermediarios por los productores-, la realidad es muy diferente. El agricultor se subordina tanto a las políticas recaudatorias estatales cuanto a los intereses de acopiadores, agroindustrias y exportadores; los recursos desembolsados son muy inferiores a los declarados -durante la campaña 2004/2005, Misiones recibió solo $\$ 70.000 .000$, en vez de los $\$ 200.000 .000$ o $\$ 300.000 .000$ que anualmente debiera percibir (Argentina, 2006; Agüero, 2009)-, y a su vez estos solo benefi- 
cian a los agentes más poderosos del circuito. Se corrobora, de ese modo, la tesis de Cariola \& Lacabana (1986), quienes sostienen que, aunque exista una transferencia sistemática de recursos desde el Estado hacia los agentes dominados de un circuito de acumulación determinado, los mecanismos de subordinación operantes en este siempre acabarán beneficiando a los agentes dominantes. Es interesante señalar que tampoco el FET ha contribuido a solucionar la problemática campesina respecto de la tenencia de la tierra: por el contrario, los productores familiares rara vez cuentan con el título de propiedad de sus parcelas -son ocupantes de hecho-.

Obligado a atenuar el 'vacío' regulatorio dejado por la mercantilización de las políticas públicas nacionales y los diezmados aportes del FET, el Estado provincial fue Ilamado a desempeñar un papel más activo en la regulación del circuito, convirtiéndose en un contemporizador de los conflictos entre campesinos y acopiadores/agroindustrias: campaña tras campaña, es convocado a arbitrar entre los intereses de ambas facciones y, sobre todo, a socorrer con recursos del tesoro público a los agricultores para evitar su quebranto; así pues, en 2011, en el momento más álgido de una de las peores crisis del tabaco a nivel mundial, cuando la sobreproducción de Brasil y Malawi inundó los mercados internacionales y los precios se desplomaron un 30\% respecto de la campaña 2008/2009, la intervención del gobierno local fue clave para permitir que los productores misioneros percibieran, pese a la tendencia general, un aumento en el valor de acopio situado en el orden del $10 \%$ respecto del ciclo agrícola anterior (Territorio Digital, 2011).

Otro factor que tiende a afianzar la reproducción socioterritorial del modelo tabacalero misionero es el carácter intensivo en mano de obra de la actividad. Oficialmente, se estima que en el circuito tabacalero -desde la producción primaria hasta la comercialización- se inserta el 3\% de la fuerza de trabajo total del país -672.700 personas-; su capacidad de generación de puestos laborales es holgadamente superior a la de otras actividades agroindustriales: el tabaco requiere, en promedio, unos 130 jornales/ha, frente a los 28/ha del algodón, los 65/ha de la caña de azúcar y los 85/ha de la vid (Corradini et al.,
2005). Sin embargo, lo anterior no asegura en modo alguno que la actividad tabacalera sea una fuente de prosperidad o movilidad social ascendente.

La etapa primaria del circuito tabacalero misionero se desarrolla en unidades minifundistas, cuya superficie promedio ronda las 25 ha, el $70 \%$ de las cuales corresponde a monte o capuera -tierra desmontada que alguna vez tuvo cultivos-. Solo el tabaco proporciona, en ese esquema productivo, un ingreso monetario a los productores, el $96,6 \%$ de los cuales posee plantaciones cuya área es menor a las 10 ha, y el 52,7\%, inferior a las 2 ha (Argentina, 2006). Si bien la extensión del calendario agrícola -330 días- y los cuidados intensivos que requiere el cultivo -todo el proceso productivo es manual, desde la preparación del suelo, los almácigos, el trasplante, el desflore y el desbrote, hasta la cosecha, el primer curado y la preclasificación en fardos- demandan un gran número de peones, la escasa capacidad de ahorro/capitalización de los campesinos determina que la fuerza laboral sea esencialmente familiar; este es un rasgo casi endémico del sector tabacalero misionero, pues en otras áreas productivas, como Salta y Jujuy, la especialización en la variedad Virginia exige el desenvolvimiento de un uso agrícola del territorio mucho más basado en la concentración de la tierra (Cuadro $N^{\circ} 4$ ), en elevados niveles de capitalización y tecnificación, y en la demanda frecuente o regular de fuerza de trabajo asalariada. En este sentido, en Misiones solo surgen excepciones durante la época de cosecha, cuando algunos productores dinámicos -menos de la tercera parte del totalcomplementan sus requerimientos laborales con la contratación aislada o estacional de fuerza de trabajo asalariada.

Otros agentes, con menos recursos materiales, despliegan, en cambio, estrategias horizontales de reproducción social: tal es el caso del ayutorio -jornada de trabajo efectuada por un grupo de personas integrado por familia/s, vecino/s, allegado/s, etc.- y el 'cambio de día' -préstamos (generalmente de herramientas) retribuidos con la venta temporal de fuerza laboral en una actividad definida por el poseedor del bien de capital (García, 2011). Son solidaridades orgánicas, que aspiran a recrear cierta cohesión sociote- 
Cuadro $N^{\circ} 4$

Explotaciones tabacaleras, según superficie y provincias seleccionadas, año 2004

\begin{tabular}{|l|r|r|r|r|r|r|r|r|}
\hline Provincia & $\begin{array}{c}\text { 0,1-2,0 } \\
\text { ha }\end{array}$ & $\begin{array}{c}2,1-5,0 \\
\text { ha }\end{array}$ & $\begin{array}{c}5,1-10,0 \\
\text { ha }\end{array}$ & $\begin{array}{c}10,1- \\
15,0 \text { ha }\end{array}$ & $\begin{array}{c}15,1- \\
20,0 \text { ha }\end{array}$ & $\begin{array}{c}20,1- \\
30,0 \text { ha }\end{array}$ & $\begin{array}{c}\text { Más de } \\
30 \text { ha }\end{array}$ & $\begin{array}{c}\text { Total } \\
\text { ha }\end{array}$ \\
\hline Misiones & 15.452 & 10.599 & 2.307 & 580 & 118 & 255 & 36 & 29.347 \\
Jujuy & 19 & 312 & 844 & 907 & 1.130 & 2.303 & 12.902 & 18.417 \\
Salta & 79 & 655 & 1.469 & 1.376 & 1.190 & 2.404 & 12.067 & 19.240 \\
Total del país & 19.576 & 14.924 & 5.877 & 3.454 & 2.657 & 5.351 & 25.717 & 77.566 \\
\hline
\end{tabular}

Fuente: Elaboración propia en base a Argentina (2006).

rritorial en el seno del campesinado, en tanto que eslabón y agente social más débil y postergado del circuito productivo tabacalero.

No existe, en verdad, correlato alguno entre el bienestar socioeconómico que el discurso hegemónico atribuye al modelo productivo reinante, y la realidad: el umbral mínimo de subsistencia de una familia tabacalera se situaba, en 2008, en 10.000 kg de tabaco -\$85.000, de los cuales los agricultores percibían el 65\% (el 35\% restante se destinaba a financiar la obra social del sector y al pago de insumos)-. Sobre una media de seis personas por grupo familiar, cada individuo obtenía, en el mejor de los casos, \$500 al mes (Agüero, 2009); esa situación representaba, empero, a la minoría privilegiada del universo de análisis: en 2005, el 40,3\% de las productores percibía ingresos inferiores a $\$ 5.000$ al año, solo el $30 \%$ de los tabacaleros rebasaba los $2.000 \mathrm{~kg}$ anuales, y apenas 28 productores superaban los 7.000 kg/año (Argentina, 2006). En la inmensa mayoría de los casos, el cultivo de tabaco no arrojaba los márgenes de rentabilidad indispensables para garantizar siquiera la simple y estricta reproducción de la economía familiar.

Operan, en tal sentido, interdependencias entabladas entre diversos factores. El agricultor es obligado a operar con un elevado margen de incertidumbre, puesto que, en el momento de la siembra, los contratos nunca estipulan cuál será el precio final que obtendrá por kilogramo de hoja de tabaco; luego, cuando entrega su cosecha al acopiador, este le abona el valor su producción en pesos, descontándole los costos financieros implicados en el adelanto de bienes y servicios al inicio del ciclo agrícola, así como también el precio de los insumos anticipados -el cual se fija en dólares, y oscila conforme a la fluctuación del tipo de cambio y la evolución del mercado mundial de agroquímicos- (García, 2011). Obligados a entregar su producción 'a cuenta' -suelen transcurrir de diez días a tres meses entre el acopio y la fecha de pago-, los campesinos perciben, a despecho del boom exportador, una porción cada vez menor de la renta tabacalera: la relación entre el valor de exportación del tabaco y el precio recibido por el productor se ha movido constantemente en perjuicio de estos últimos: si durante el quinquenio 1997-2001 el agricultor recibió, en promedio, el $80 \%$ del precio de exportación, en los cuatrienios 2002-2005 y 2006-2009 obtuvo el $65,7 \%$ y el $61,5 \%$, respectivamente (Slutzky, 2011).

Los campesinos sufren, asimismo, importantes demoras en las remesas de recursos del FET, especialmente en lo que atañe a los sobreprecios que complementan los valores pagados por la agroindustria; se trata de montos ínfimos -en 2010, \$0,35 por kg-, pero para la mayoría de los productores esos recursos equivalen al mínimo margen de ganancia que obtienen luego de entregar el producto anual de su trabajo. Otra trampa del tabaco concierne a las múltiples categorías -y preciosde Burley que segmentan el mercado, y a las rigurosas exigencias de calidad impuestas por los acopiadores: el mejor precio corresponde a la categoría ' $A$ ', pero el grueso de las cosechas suele ser pagado como calidad ' $\mathrm{B}$ ' o 'C', razón por la cual cada miembro del grupo familiar obtenía, a mediados de la primera década del siglo XXI, un promedio de $\$ 200$ mensuales -U\$S 45-, equivalentes al importe de un plan social por desocupación (Agüero, 2009). 
No es extraño, pues, que un autor como Slutzky (2011) asevere que las condiciones de vida de los campesinos son infrahumanas: residen, hacinados, en viviendas extremadamente precarias, emplazadas en parcelas con graves problemas de regularización de tenencia de la tierra, construidas de madera y con piso de tierra, en su mayoría carentes de agua potable y servicios sanitarios -el $80 \%$ no posee retrete, y la mitad carece de energía eléctrica-; concomitantemente, se observaban elevados niveles de analfabetismo $(3,6 \%)$ y semianalfabetismo -escolaridad primaria incompleta $(45,5 \%)$ - entre los colonos y sus familias (Argentina, 2006), naturalmente derivados de la imperiosa necesidad (especialmente durante la época de cosecha) de incluir a los niños al proceso de trabajo y, así, satisfacer los volúmenes de producción pactados con los acopiadores.

Ante tal estado de cosas, cabría inquirir: ¿por qué los agricultores misioneros continúan plantando tabaco? Organizador y centralizador de la vida familiar, el tabaco constituye casi la única producción destinada al mercado, y prácticamente la única fuente de renta, complementada marginalmente por la yerba-mate, la mandioca y la ganadería; esto hace desistir a los agricultores de abandonar la actividad, aun cuando esta, lejos de garantizar una reproducción digna de sus más elementales condiciones de existencia, exacerba su dependencia respecto de las políticas públicas y las cambiantes e ignominiosas condiciones contractuales impuestas por el eslabón acopiador/agroindustrial del circuito. Es que, una vez que el agricultor familiar ha ingresado en el circuito del endeudamiento y provisión de materia prima, le resulta extremadamente difícil salir del mismo y, por ende, poner fin a esa dependencia; esto sucede por motivos básicamente económicos, puesto que la deuda por los insumos adelantados opera como un mecanismo que coarta la libertad de elección de aquel respecto a qué y cómo producir y vender: el sucesivo y/o progresivo endeudamiento del productor -que en la mayoría de los casos puede refinanciar sus deudas año tras año- implica, de hecho, continuar entregando su capacidad de decisión futura a un sistema agroindustrial que, paulatinamente, lo despoja de toda autonomía (García, 2010).
Ni siquiera cuando el campesino, por razones ajenas a su voluntad, es expulsado del circuito, consigue escapar al yugo del tabaco; tal es el caso de los agricultores que producen materia prima sin contrato, fenómeno que se ha tornado frecuente desde mediados de la primera década del siglo XXI. Originada a partir de diversos factores -el incumplimiento de los volúmenes oportunamente pactados, la negativa empresaria a refinanciar las deudas de ciertos productores, las deudas tributarias con el Estado (vinculadas a la falta de pago del monotributo) y prácticas expresamente prohibidas, como el contrabando a Brasil o el cultivo con semillas caseras-, la rescisión de los contratos -o la decisión del acopiador de excluir al productor de la próxima planificación del ciclo agroindustrial- convierte a los campesinos en tercerizados -también llamados 'echos' o 'echados', en la jerga local-; al quedar fuera del circuito legal y no hallar otras alternativas productivas viables, una estrategia de supervivencia consiste en 'desviar' tabaco, esto es, vendérselo a un comerciante (generalmente, un vecino, familiar, amigo o allegado), quien les adelanta los insumos sin la intermediación de un contrato escrito. Según explica García (2011), esto genera dos nuevas formas de precarización laboral: o bien el comprador adquiere el tabaco antes o después de la cosecha, y el agricultor debe contentarse con un precio situado entre un $25 \%$ y un $35 \%$ por debajo del valor de acopio oficial, aceptando quedar relegado de otros beneficios, como los sobreprecios del FET y el acceso a la obra social; o bien el comerciante entrega el tabaco a la empresa y se apropia del dinero del retorno y otros recursos públicos, pero participando al campesino de una parte de los sobreprecios otorgados por el FET. Se trata, pues, de circuitos paralelos, horizontales, irracionales, indirectamente articulados -pero siempre completamente subordinados- a la racionalidad hegemónica impuesta por el capital transnacional.

\section{Conclusiones}

Objeto de repetidos y dramáticos episodios de reestructuración, el tabaco Burley ganó dinamismo en la provincia de Misiones durante la década de 1990, cuando la nueva lógica exportadora se instaló en el territorio 
local para responder a las estrategias de integración vertical del eslabón agroindustrial/ comercial del circuito. Obedeciendo a las políticas de los países consumidores y a los intereses de las firmas globales, la cientifización del trabajo agrícola, la propagación de los OGM's y los agrotóxicos, la cronoexpansión de la frontera agropecuaria y la agricultura contractual se consolidaron y expandieron, siempre acompañadas por un discurso en el cual el tabaco aparece como una producción respetuosa del ambiente y la salud, a despecho de la peligrosidad de los agroquímicos utilizados, los elevados niveles de contaminación y los alarmantes padecimientos sanitarios de la franja poblacional involucrada; se lo considera un elemento imprescindible para el desarrollo social regional, aun cuando las asimetrías del circuito no permiten (en el mejor de los casos) más que la reproducción básica de las míseras condiciones de vida del campesinado; $y$, paradójicamente, se invoca al Fondo Especial del Tabaco como ente burocrático esencial para mitigar las problemáticas del sector y reorientar a los agricultores hacia producciones más viables/rentables, aunque sus políticas agudicen las desigualdades preexistentes, favorezcan al capital y perpetúen el modelo, exacerbando el grado de subordinación del agricultor respecto de la racionalidad hegemónica del capital transnacional. Tal como lo sintetiza García (2010), se trata de un modelo de acumulación empresarial basado en el perjuicio a la salud de los productores y sus familias, la extracción de renta mediante usurarias tasas aplicadas a los insumos adelantados, el abuso del poder de mercado y el trabajo infantil.

Opera bajo la forma de la agricultura contractual, uno de los principales mecanismos de acumulación capitalista que coadyuva al desarrollo, en el territorio misionero, del desorden local como correlato directo del orden global: contaminación, pauperización, subordinación, enfermedades y crisis social constituyen, pues, la cara oculta (y la consecuencia estructural) del reciente boom exportador. Obstando su acción compensadora para regular el circuito, los actores políticos nacionales y locales tienden a reforzar el círculo vicioso de pobreza rural, pues desmantelan sistemáticamente todos los planes de reestructuración y diversificación econó- mica que desde el mismo aparato estatal se proponen para alentar a los campesinos a abandonar, a mediano plazo, el cultivo de tabaco. Evidentemente, esto es funcional a intereses espurios: por un lado, el Estado no está dispuesto a renunciar al generoso caudal de recursos fiscales que aporta la industria tabacalera, y que en buena medida depende de la especialización del campesinado en dicha actividad y su apego a la misma por tradición, necesidad y subordinación (no por rentabilidad); por otro lado, agroindustrias y acopiadores tampoco desean perder la posición privilegiada de poder que detentan, la cual les permite disciplinar al campesinado, controlar la producción primaria -pero sin correr los riesgos que implicaría intervenir directamente en esta-, aprovechar los beneficios que supone una oferta atomizada y un mercado oligopsónico, y extraer de los agricultores la plusvalía derivada tanto de la autoexplotación de la fuerza de trabajo familiar cuanto de la inexistencia de vínculo laboral alguno con la misma. Se perpetúan, así, los mecanismos que desarticulan toda posibilidad de que el campesino escape a la trampa que supone su inserción subordinada en la lógica globalizada del circuito tabacalero de exportación.

\section{Referencias bibliográficas}

AGÜERO, J.O. La cuestión social en Argentina. Los tabacaleros en Jujuy y Misiones. Buenos Aires: Dunken, 2009.

ARGENTINA. Censo Nacional Agropecuario 2002. Resultados definitivos, por cultivos, provincias y departamentos. Buenos Aires: Instituto Nacional de Estadística y Censos, 2005.

ARGENTINA. Explotaciones agropecuarias tabacaleras en la Argentina. Caracterización en base al Censo Nacional Agropecuario 2002. Buenos Aires: Ministerio de Agricultura, Ganadería y Pesca, 2006.

ARGENTINA. Censo Nacional Económico 2004. Resultados definitivos, por sectores. Buenos Aires: Instituto Nacional de Estadística y Censos, 2007.

ARGENTINA. Consumo aparente de cigarrillos (1910-2011). Buenos Aires: Ministerio de Agricultura, Ganadería y Pesca, 2012. 
BARANGER, D. Tabaco y agrotóxicos. Un estudio sobre productores de Misiones. Posadas: Editorial Universitaria de Misiones, 2007.

BARANGER, D. y CASTIGLIONI, G. Las representaciones sobre la salud y las prácticas. En: BARANGER, D. (coordinador). Tabaco y agrotóxicos. Un estudio sobre productores de Misiones. Posadas: Editorial Universitaria de Misiones, 2007, p. 38-55.

BARSKY, O. Políticas agrarias en América Latina. Buenos Aires: Imago Mundi, 1990.

BECK, U. La sociedad del riesgo. Hacia una nueva modernidad. Buenos Aires: Paidós, 1993.

BERTONI, L. y GRAS, C. El complejo tabacalero en la desregulación. Actores, negociaciones y conflictos. En: MARTíNEZ DE IBARREÑA, M.; POSADA, M. y PUCCIARELLI, P. (compiladores). Estudios agroindustriales. Buenos Aires: CEAL, 1994, p. 191-213.

BRIGNOL, R. y CRISPI, J. El campesinado en América Latina. Una aproximación teórica. Revista de la CEPAL, 1982, № 16, p. 144-154.

CÁCERES, D. Lógica práctica, estructura tecnológica y abordaje productivo. Una perspectiva dinámica. Revista Interdisciplinaria de Estudios Agrarios, 2004, № 20, p. 5-40.

CÁCERES, D. Tecnologías modernas: la perspectiva de los pequeños productores. Cuadernos de Desarrollo Rural, 2009, Vol. 62, No 6, p. 121-143.

CARIOLA, C. y LACABANA, M. Circuitos de acumulación: una perspectiva de análisis integral para la planificación regional. Cuadernos del CENDES, 1986, Vol. 2, № 5, p. 65-110.

CONABIA. OVGM liberados al medio (1991-2004). Buenos Aires: Comisión Nacional Asesora de Biotecnología Agropecuaria, 2006.

CORRADINI, E.; CUESTA, R.; MERELLO, P.; SEGESSO, R.; GIMÉNEZ, M. L.; ZILOCCHI, H.; MOLFESA, S. y MUSCO, J. M. Caracterización del sector productor tabacalero en la República Argentina. Buenos Aires: Universidad Católica Santa María de los Buenos Aires, 2005.
COTTAPROM. Uso de agroquímicos en el cultivo de tabaco. Provincia de Misiones, Argentina. Posadas: Comisión Técnica de Tabaco de la provincia de Misiones, 2012.

DOMínGuEZ, C. Territorio, produit et conventions. La dynamique tabacote sur le front pionnier de la province argentine de $\mathrm{Mi}$ siones. A la croisée de plusieurs monde. Tesis doctoral en Developpement rural. Toulouse: Universite Toulouse Le Mirail, 1995.

DUTRA, R. Plantadores de tabaco y riesgos socioambientales de los métodos de utilización de plaguicidas en San Vicente (Misiones, Argentina). Porto de Galinhas-RecifePernambuco: REDISEC, 2010.

GALLERO, M.C. Con la patria a cuestas. La inmigración alemana-brasileña en la Colonia Puerto Rico, Misiones. Buenos AiresResistencia: Araucaria Editora, 2009.

GALLERO, M. C. Tabacaleros y acopiadores en la colonización del Alto Paraná Misionero (1930-1946). Mundo Agrario, 2011, Vol. 22. No 11. Disponible en internet: http://www.scielo.org.ar/pdf/magr/v11n22/ v11n22a04.pdf

GARCÍA, A. Agroindustria, agricultura familiar, políticas públicas. Contratos de producción tabacalera en Misiones y Río Grande do Sul. Tesis de doctorado en Geografía. Buenos Aires: UBA, 2010.

GARCÍA, A. Adaptaciones frente a una relación asimétrica: agricultores familiares y agroindustrias en el nordeste de Misiones (Argentina). Estudios Socioterritoriales. Revista de Geografía, 2011, № 10, p. 41-64.

GIRBAL-BLACHA, N. Estado y regulación económica en el norte argentino. El tabaco en la década de 1930. Historia agraria. Revista de agricultura e historia rural, 2007, N 41, p. 83-105.

GÓMEZ LENDE, S. La naturaleza como construcción social. La ingeniería genética y la crono-expansión de la frontera agropecuaria. Revista Universitaria de Geografía, 2006, No 15, p. 11-35. 
GRAS, C. Complejos agroindustriales y globalización: Cambios en la articulación del sector agrario. International Journal of Sociology of Agriculture and Food, 1997, No 6, p. 55-75.

GORTARI, J. De la tierra sin mal al tractorazo. Posadas: Editorial Universitaria de Misiones, 2007.

GOTTMANN, J. The evolution of the concept of territory. Information sur les Sciences Sociales, 1975, Vol. 2, No 14, p. 29-47.

GUILLAUME, M. Le capital et son double. París: Presses Universitaires de France, 1975.

HERNÁNDEZ, V. La ruralidad globalizada y el paradigma de los agronegocios en las pampas gringas. En: GRAS, C. y HERNÁNDEZ, V. (coordinadores). La Argentina rural: de la agricultura familiar a los agronegocios. Buenos Aires: Biblos, 2009, p. 39-64.

MARSDEN, T.; MUNTON, R.; WARD, N. \& WHATMORE, S. Agricultural geography and the political economy approach: a review. Economic Geography, 1996, Vol. 4, No 72, p. 361-375.

MARQUÉS, N. Agentes sociales, eslabonamientos productivos y diagnósticos regionales. Buenos Aires: ILPES-CEPAL-ONU, 1987.

MARX, K. El capital. Crítica de la economía política. México D.F.: Fondo de Cultura Económica, 1980.

MORAES, A.C.R. Los circuitos espaciales de producción y los círculos de cooperación en el espacio". En: LIBERALI, A.M. y YANES, L. (organizadores). Aportes para el estudio del espacio socioeconómico (III). Buenos Aires: El Coloquio, 1988, p. 151-177.

PÁEZ, S. Uso de agrotóxicos en el cultivo de tabaco: sus consecuencias en los actores sociales y en el espacio geográfico de la zona centro de la Provincia de Misiones, Argentina. Posadas: Geoperspectivas, 2008. Disponible en internet: http://geoperspectivas.blogspot.com

ROCA, J-P. Les geographes tropicalistes et la technique. En: BRUNEAU, M. \& DORY,
D. (compilador). Les enjeux de la tropicalité. París: Masson, 1989, p. 119-127.

ROFMAN, A.; GARCÍA, A.; GARCÍA, L.; LAMPREABE, F.; RODRÍGUEZ, E. y VÁZQUEZ BLANCO, J.M. Subordinación productiva en las economías regionales de la posconvertibilidad. Crecimiento económico y exclusión social en los circuitos del tabaco, la vid, el azúcar, el algodón y el olivo. Realidad Económica, 2008, Nº 240, p. 97-132.

SANTOS, M. Espaço e método. São Paulo: Nobel, 1992.

SANTOS, M. A natureza do espaço. Técnica e tempo, razão e emoção. São Paulo: Hucitec, 1996a.

SANTOS, M. De la totalidad al lugar. Barcelona: Oikos-Tau, 1996 b.

SANTOS, M. Por uma outra globalização. Do pensamemto único ã consciência universal. Rio de Janeiro-São Paulo: Record, 2000.

SANTOS, M. \& SILVEIRA, M. L. O Brasil. Território e sociedade no início do século XXI. Rio de Janeiro-São Paulo: Record, 2001.

SILVEIRA, M.L. Um país, uma região. Fim de século e modernidades na Argentina. São Paulo: FAPESP-LABOPLAN-USP, 1999.

SLUTZKY, D. Estructura social agraria y agroindustrial del nordeste de la Argentina: desde la incorporación a la economía nacional al actual subdesarrollo concentrador y excluyente. Buenos Aires: IADE, 2011.

TEUBAL, M. El agribusiness y la transnacionalización de la agricultura latinoamericana. En: TEUBAL, M.; GIARRACA, N. y PASTORE, R. (organizadores). Globalización y expansión agroindustrial: ¿Superación de la pobreza en América Latina? Buenos Aires: Corregidor, 1995, p. 81-105.

TEUBAL, M. y PASTORE, R. El agro y los complejos agroindustriales: el caso argentino. En: TEUBAL, M.; GIARRACA, N. y PASTORE, R. (organizadores). Globalización y expansión agroindustrial: ¿Superación de la pobreza en América Latina? Buenos Aires: Corregidor, 1995, p. 107-135. 